BMJ Open

Diabetes

Research

\& Care

\section{Gestational diabetes and long-term risk for dyslipidemia: a population-based historical cohort study}

To cite: Chodick G, Tenne Y, Barer Y, et al. Gestational diabetes and long-term risk for dyslipidemia: a populationbased historical cohort study. BMJ Open Diab Res Care 2020;8:e000870. doi:10.1136/ bmjdrc-2019-000870

- Additional material is published online only. To view please visit the journal online (http://dx.doi.org/10.1136/ bmjdrc-2019-000870).

Received 5 September 2019 Revised 27 December 2019 Accepted 28 December 2019

\section{Check for updates}

\section{(C) Author(s) (or their} employer(s)) 2020. Re-use permitted under CC BY-NC. No commercial re-use. See rights and permissions. Published by BMJ.

${ }^{1}$ Maccabi Institute Research and Innovation, Maccabi Healthcare Services, Tel Aviv, Israel

${ }^{2}$ Tel Aviv University Sackler Faculty of Medicine, Tel Aviv, Israel

${ }^{3}$ Hadassah University Hospital, Jerusalem, Israel

Correspondence to Dr Gabriel Chodick; hodik_g@mac.org.il

\section{ABSTRACT}

Objectives To assess the course of lipid levels over time in postpartum women according to gestational diabetes status, taking into account potential confounders, such as comorbid conditions and body weight.

Methods The data for the present analysis were collected from a 2.3 million member integrated care provider in Israel. Included were all female members aged 15-50 years who performed a $50 \mathrm{~g}$ glucose challenge test (GCT) between March 1995 and May 2009. We collected all follow-up lipid consecration tests performed from date of delivery following the GCT (index date) until April 2017. Data analysis was performed for each lipid component individually (triglyceride (TG), low-density lipoprotein cholesterol (LDL-C), and high-density lipoprotein cholesterol (HDL-C)) and the effects of the several risk factors (history of gestational diabetes mellitus (GDM), age at delivery, obesity status and smoking status) were investigated using general linear model taking into account potential confounders.

Results A total of 160527 women (6.1 million personyears of actual follow-up) were eligible for the analysis, including 10234 women with GDM $(6.4 \%$ of the entire cohort). During the study follow-up period, a total of 2.1 million lipid tests were performed. When adjusting for follow-up time, age at index date, body mass index status, and smoking status, GDM was associated with a 1.8-fold risk $(95 \% \mathrm{Cl} 1.73$ to 1.88 ) for dyslipidemia defined by TG, 1.45 -fold risk ( $95 \% \mathrm{Cl} 1.38$ to 1.52) for dyslipidemia defined by LDL-C, and 1.44 -fold risk ( $95 \% \mathrm{Cl} 1.39$ to 1.50$)$ for dyslipidemia defined by HDL-C.

Discussion The results of this retrospective cohort analysis indicate that gestational diabetes confers added risk for developing hyperlipidemia post partum, particularly dyslipidemia defined by TG, as compared with women with normal glucose tolerance.

\section{INTRODUCTION}

Gestational diabetes mellitus (GDM) is defined as carbohydrate intolerance first diagnosed in the second or third trimester of the pregnancy. ${ }^{1}$ The prevalence of this gestational complication is between $1 \%$ and $28 \%$ of pregnancies ${ }^{2}$ and rising over time. ${ }^{3}$ GDM is associated with short and long-term outcomes for both mother and child. ${ }^{4}$

Women with GDM history are at an increased risk for developing major cardiovascular risk

\section{Significance of this study}

What is already known about this subject?

- While it has been suggested that women with gestational diabetes mellitus (GDM) history may have higher prevalence of dyslipidemia, data from large and long-term studies are lacking.

What are the new findings?

- Women with history of gestational diabetes have a significantly greater risk for dyslipidemia defined by triglyceride, low-density lipoprotein cholesterol, and high-density lipoprotein cholesterol.

How might these results change the focus of research or clinical practice?

- The study results underline the need for an increased awareness among patients and caregivers and focusing on healthy lifestyle modification to mitigate the risk of dyslipidemia among women with GDM history.

factors, such as type 2 diabetes, ${ }^{5-8}$ metabolic syndrome,${ }^{9}$ hypertension ${ }^{10}$ and subclinical ${ }^{11}$ and clinical ${ }^{12}$ atherosclerosis. The increased risk for complications has been documented despite normalizations of glucose levels shortly after delivery. ${ }^{13}$ However, less attention has been given to the association between GDM and long-term risk of dyslipidemia, a metabolic disorder characterized by elevated levels of low-density lipoprotein cholesterol (LDL-C), low levels of high-density lipoprotein cholesterol (HDL-C), and elevated levels of triglycerides (TG).

While it has been suggested ${ }^{14}$ that women with GDM history are characterized by higher prevalence of dyslipidemia compared with their normoglycemic peers, analysis of parous women from the 2007 to 2014 cycles of the National Health and Nutrition Examination Survey indicated that history of GDM is not significantly related with increasing levels of LDL-C. ${ }^{15}$ Thus, the aims of the current historical cohort study were to assess the course of lipid levels over time in postpartum women 
according to gestational diabetes status, taking into account potential confounders, such as comorbid conditions and body weight.

\section{METHODS}

The data for the present analysis were collected from the central mainframes of Maccabi Healthcare Services (MHS), a 2.3 million member integrated care provider in Israel.

\section{Study population}

Included were all female MHS members who performed a $50 \mathrm{~g}$ glucose challenge test (GCT) between March 1995 and May 2009 (to allow at least 9 years of potential retrospective follow-up) and were aged 15-50 years at day of testing with at least one lipid test post partum. We excluded all women who had pre-existing diabetes mellitus, dyslipidemia, or infertility treatments. Date of delivery following the GCT was defined as index date. If a woman had several pregnancies during the study observation period, the most recent one was selected.

\section{GDM definition}

In MHS, all pregnant women are routinely screened for GDM with a $50 \mathrm{~g}$ GCT between 24 and 28 weeks of gestation. Women with a serum glucose concentration $>140 \mathrm{mg} / \mathrm{dL}(7.8 \mathrm{mmol} / \mathrm{L}) 1$ hour after GCT are referred to a diagnostic $100 \mathrm{~g}$ oral glucose tolerance test (OGTT). GDM was defined according to Carpenter and Coustan, ${ }^{16}$ based on the presence of two or more of the following values in the OGTT: fasting serum glucose $\geq 95 \mathrm{mg}$ / dL $(5.3 \mathrm{mmol} / \mathrm{L}), 1$ hour serum glucose $\geq 180 \mathrm{mg} / \mathrm{dL}$ $(10.0 \mathrm{mmol} / \mathrm{L})$, 2 hours serum glucose $\geq 155 \mathrm{mg} / \mathrm{dL}$ $(8.6 \mathrm{mmol} / \mathrm{L})$ or 3 hours serum glucose $\geq 140 \mathrm{mg} / \mathrm{dL}$ $(7.8 \mathrm{mmol} / \mathrm{L})$, all other women were defined as nonGDM. Further subcategorization was made according to obesity status and smoking status. Prepregnancy obesity status prior to conception was defined according to documented body mass index (BMI) taken at least 1 year prior to date of delivery and was categorized into normal weight (BMI $<25 \mathrm{~kg} / \mathrm{m}^{2}$ ), overweight (BMI 25-29 kg/ $\mathrm{m}^{2}$ ), and obesity (BMI $\left.\geq 30 \mathrm{~kg} / \mathrm{m}^{2}\right)$. Smoking status was categorized into non-smoker, past or current.

\section{Dyslipidemia}

We collected all follow-up lipid consecration tests performed from index date until April 2017. Data analysis was performed for each lipid component individually (TG, LDL-C, and HDL-C) and the effects of the several risk factors (history of GDM, age at delivery, obesity status and smoking status) were investigated. Dyslipidemia was defined according to the Adult Treatment Panel III, ${ }^{17}$ which was the relevant guidelines for the time of the study period: $\mathrm{TG}>200 \mathrm{mg} / \mathrm{dL}(2.26 \mathrm{mmol} / \mathrm{L})$, LDL-C $>160 \mathrm{mg} / \mathrm{dL} \quad(4.14 \mathrm{mmol} / \mathrm{L})$ and HDL-C $<40 \mathrm{mg} / \mathrm{dL}$ $(1.30 \mathrm{mmol} / \mathrm{L})$. For LDL-C follow-up, initiation of statin therapy was defined as censor. All study patients had at least one measurement of TG, $99.5 \%$ and $77.4 \%$ had at least one HDL and LDL measure, respectively.

\section{Other study variables}

Socioeconomic level was categorized into quartiles according to the poverty index of the member's enumeration area as defined by the 1995 national census based on several parameters including household income, educational qualifications, crowding, material conditions, and car ownership.

\section{Statistical analysis}

Baseline characteristics were compared between women with history of GDM to those without, by $\chi^{2}$ for categorical variables and by t-test for continuous variables.

We used general linear model to assess the influence of several risk factors such as: time since delivery, history of GDM, women's age at delivery, obesity status and smoking status on the risk of an increase in lipid levels. Significant level was set at $\mathrm{p}=0.05$.

We used Cox proportional hazards regression model to estimate the adjusted HR of history of GDM to the development of dyslipidemia (for each component separately). The proportional hazard assumption was checked graphically and found to reasonably fulfill.

\section{RESULTS}

A total of 160527 women (6.1 million person-years of actual follow-up) were eligible for the analysis, including 10234 women with GDM (6.4\% of the entire cohort). Baseline characteristics of GDM status are presented in table 1. Patients with GDM were more likely to be older (31.45 years vs 33.24 years), overweight or obese (11\% vs $17.3 \%$ and $7.6 \%$ vs $20.6 \%$, respectively) and to have a single delivery during the study period $(50.7 \%$ vs $88.3 \%)$.

During the study follow-up period, a total of 2.1 million lipid tests were performed. When adjusting for follow-up time, age at index date, BMI status, smoking status and baseline lipid levels using general linear models, we found participants with history of GDM to have $5 \mathrm{~mL} / \mathrm{dL}$ increase in TG levels, $0.7 \mathrm{mg} / \mathrm{dL}$ decrease in HDL-C level and $0.65 \mathrm{mg} / \mathrm{dL}$ increase in non-HDL-C levels, compared with those without history of GDM. Trends in lipid levels over follow-up time are given in figures 1-3. Stratified figures by age and BMI are shown in online supplementary appendix.

A total of $99.3 \%$ of the study population were tested for blood lipids and the cumulative risk of LDL-C, HDL-C, and TG dyslipidemia during the follow-up period (mean 11 years) was $11.9 \%, 24.3 \%$, and $13.3 \%$, respectively. In a multivariable survival analysis adjusting for age, BMI, and smoking status, GDM was associated with a 1.8-fold risk (95\% CI 1.73 to 1.88$)$ for dyslipidemia defined by TG, 1.45-fold risk (95\% CI 1.38 to 1.52) for dyslipidemia defined by LDL-C, and 1.44-fold risk (95\% CI 1.39 to 1.50) for dyslipidemia defined by HDL-C. HRs adjusted for baseline lipid levels are also presented in table 2 . 
Table 1 Baseline and end of follow-up characteristics of study participants, by GDM status

\begin{tabular}{|c|c|c|c|c|c|c|}
\hline \multirow{3}{*}{ Age } & \multicolumn{4}{|c|}{ Gestational diabetes } & \multirow{2}{*}{\multicolumn{2}{|c|}{$\begin{array}{l}\text { Total } \\
\text { (n=160 527) }\end{array}$}} \\
\hline & \multicolumn{2}{|c|}{ No $(n=150$ 293) } & \multicolumn{2}{|c|}{ Yes $(n=10234)$} & & \\
\hline & & & & & & \\
\hline Years, mean $( \pm S D)$ & 31.45 & $( \pm 5.02)$ & 33.24 & $( \pm 5.42)$ & 31.07 & $( \pm 5.08)$ \\
\hline \multicolumn{7}{|l|}{ Socioeconomic status } \\
\hline Lowest quartile & 27395 & 18.2 & 1974 & 19.3 & 29369 & 18.3 \\
\hline Second & 57181 & 38 & 3608 & 35.5 & 60789 & 37.9 \\
\hline Third & 26003 & 17.3 & 1890 & 18.5 & 27893 & 17.4 \\
\hline Highest & 34795 & 23.2 & 2415 & 23.6 & 37210 & 23.2 \\
\hline NA & 4919 & 3.3 & 347 & 3.4 & 5266 & 3.3 \\
\hline \multicolumn{7}{|l|}{ Smoking } \\
\hline Current & 16118 & 10.7 & 1094 & 10.7 & 17212 & 10.7 \\
\hline Past & 3027 & 2 & 231 & 2.3 & 3258 & 2 \\
\hline Never & 125204 & 83.3 & 8559 & 83.6 & 133763 & 83.3 \\
\hline Unknown & 5944 & 4 & 350 & 3.4 & 6294 & 3.9 \\
\hline \multicolumn{7}{|l|}{ Parity } \\
\hline 1 & 76126 & 50.7 & 9034 & 88.3 & 85160 & 53.1 \\
\hline 2 & 47461 & 31.6 & 1019 & 10 & 48480 & 30.2 \\
\hline 3 & 18719 & 12.5 & 160 & 1.6 & 18879 & 11.8 \\
\hline $4+$ & 7987 & 5.3 & 21 & 0.2 & 8008 & 5 \\
\hline \multicolumn{7}{|l|}{ Body weight } \\
\hline Normal or underweight & 33404 & 22.2 & 1576 & 15.4 & 34980 & 21.8 \\
\hline Overweight & 16556 & 11 & 1766 & 17.3 & 18322 & 11.4 \\
\hline Obese & 11694 & 7.6 & 2111 & 20.6 & 13805 & 8.6 \\
\hline NA & 88639 & 59 & 4781 & 46.7 & 93420 & 58.2 \\
\hline \multicolumn{7}{|l|}{ Lipids levels } \\
\hline $\mathrm{TG}$, mean log $(\mathrm{mg} / \mathrm{dL})( \pm \mathrm{SD})$ & 1.95 & $( \pm 0.21)$ & 2.06 & $( \pm 0.23)$ & 1.95 & $( \pm 0.21)$ \\
\hline LDL-C, mean mg/dL ( $(\mathrm{SD})$ & 107.05 & $( \pm 26.66)$ & 111.13 & $( \pm 31.26)$ & 107.48 & $( \pm 28.87)$ \\
\hline HDL-C mean mg/dL ( $(\mathrm{SD})$ & 54.33 & $( \pm 12.46)$ & 52.02 & $( \pm 12.59)$ & 54.18 & $( \pm 12.48)$ \\
\hline \multicolumn{7}{|l|}{ End of follow-up } \\
\hline Mean TG tests $( \pm \mathrm{SD})$ & 1.18 & $( \pm 0.53)$ & 1.27 & $( \pm 0.63)$ & 1.19 & $( \pm 0.54)$ \\
\hline Mean LDL-C tests $( \pm S D)$ & 1.16 & $( \pm 0.48)$ & 1.24 & $( \pm 0.6)$ & 1.17 & $( \pm 0.49)$ \\
\hline Mean HDL-C tests $( \pm \mathrm{SD})$ & 1.17 & $( \pm 0.49)$ & 1.25 & $( \pm 0.6)$ & 1.17 & $( \pm 0.5)$ \\
\hline Mean follow-up years $( \pm S D)$ & & 4.75 & 11 & 4.64 & 10.85 & $( \pm 4.75)$ \\
\hline Incident DM & & 0.7 & 1012 & 9.9 & 1994 & 1.2 \\
\hline
\end{tabular}

DM, diabetes mellitus; GDM, gestational diabetes mellitus; HDL-C, high-density lipoprotein cholesterol; LDL-C, low-density lipoprotein cholesterol; NA, not applicable; TG, triglyceride.

In addition to GDM, age and smoking, baseline BMI was also strongly related to dyslipidemia. Weaker associations were observed with dyslipidemia defined by HDL. Overweight, but not obesity, was also significantly $(p<0.01)$ associated with dyslipidemia defined by LDL-C with an HR.

\section{DISCUSSION}

The results of this retrospective cohort analysis indicate that gestational diabetes confers added risk for developing hyperlipidemia post partum, particularly dyslipidemia defined by TG, as compared with women with normal glucose tolerance. We also found that HDL-C is significantly lower in women who develop GDM, and that the gap develops within months post partum. Similarly, the elevated postpartum LDL-C levels in GDM women remain relatively stable, while increasing with age among normal glucose tolerance women.

Our findings corroborate the results of a previous study ${ }^{18}$ indicating that while patients with GDM history 


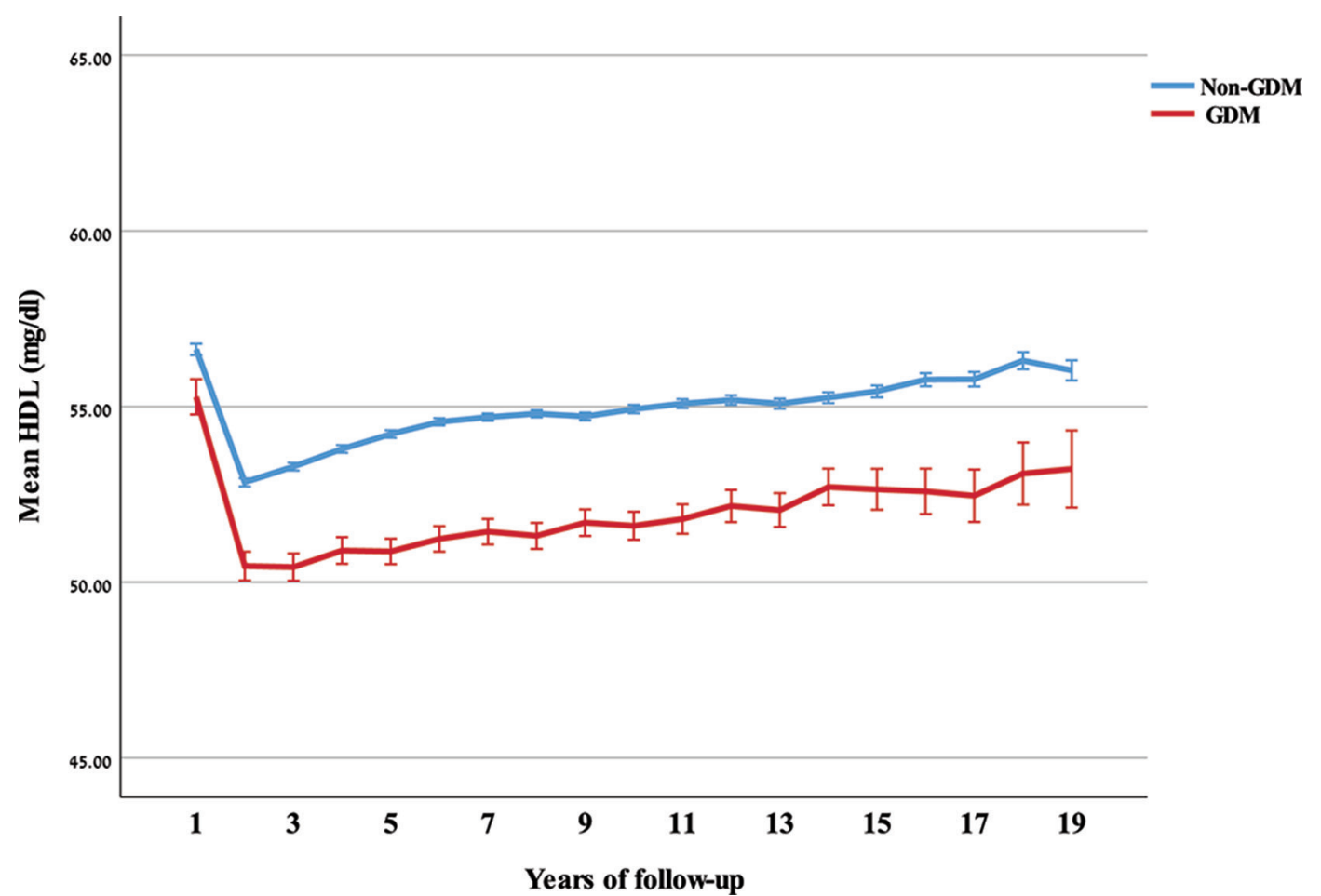

Figure 1 Mean and $95 \% \mathrm{Cl}$ of high-density lipoprotein cholesterol (HDL-C) over years of follow-up, by gestational diabetes mellitus (GDM) status.

show similar lipid profile during screening, but by 3 months post partum, there were significant differences in total cholesterol, LDL, TGs, and total cholesterolto-HDL ratio. Long-term trends in lipid profile in women with previous GDM were rarely investigated. In a cross-sectional study ${ }^{19}$ among women after an average of 30 years from delivery, responders with GDM history were more likely to demonstrate an atherogenic lipid profile, treated for dyslipidemia (ie, statins), and to be diagnosed with lipidemia at a younger age. Their overall OR for

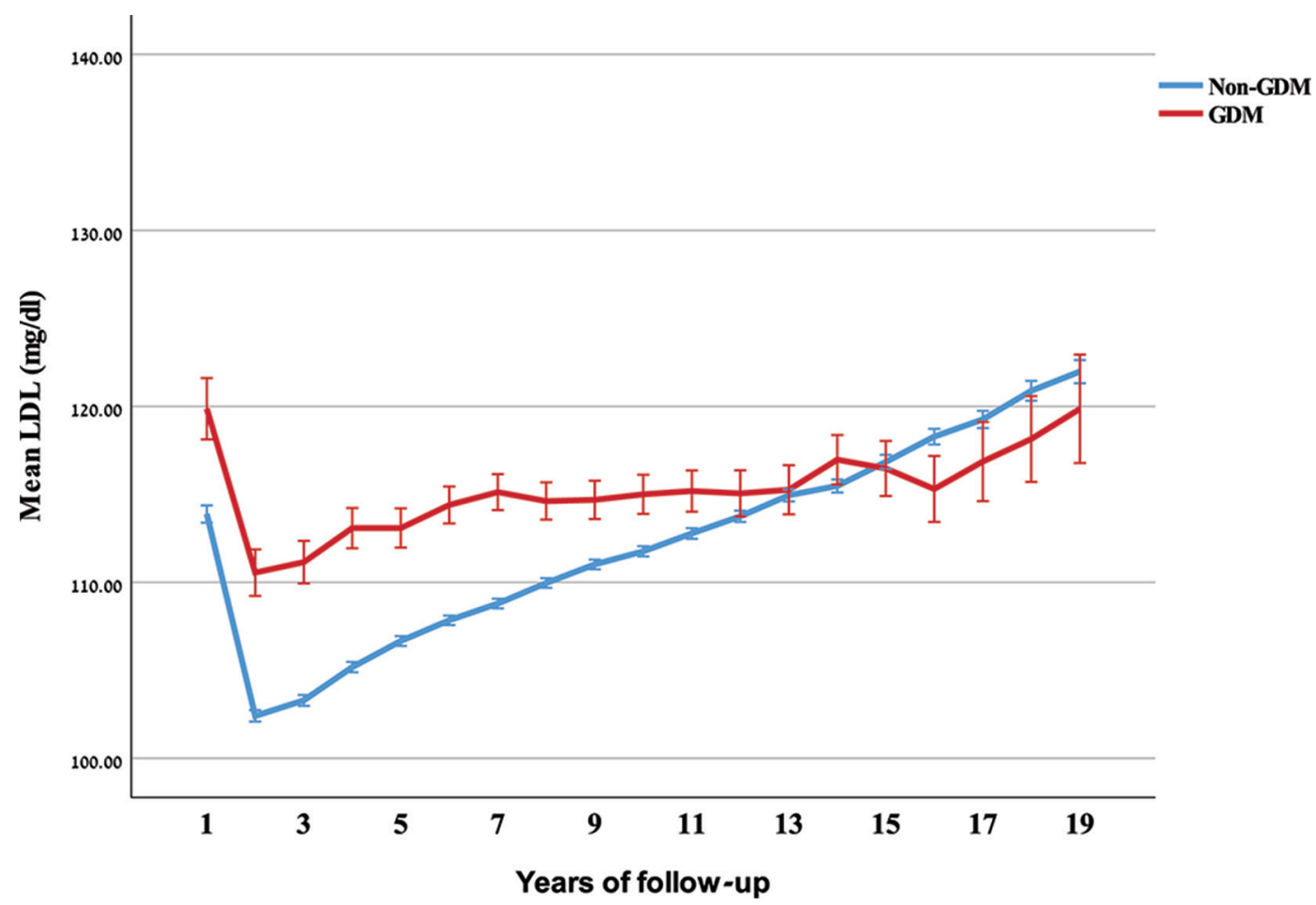

Figure 2 Mean and 95\% Cl of low-density lipoprotein cholesterol (LDL-C), and triglyceride (TG) over years of follow-up, by gestational diabetes mellitus (GDM) status. 


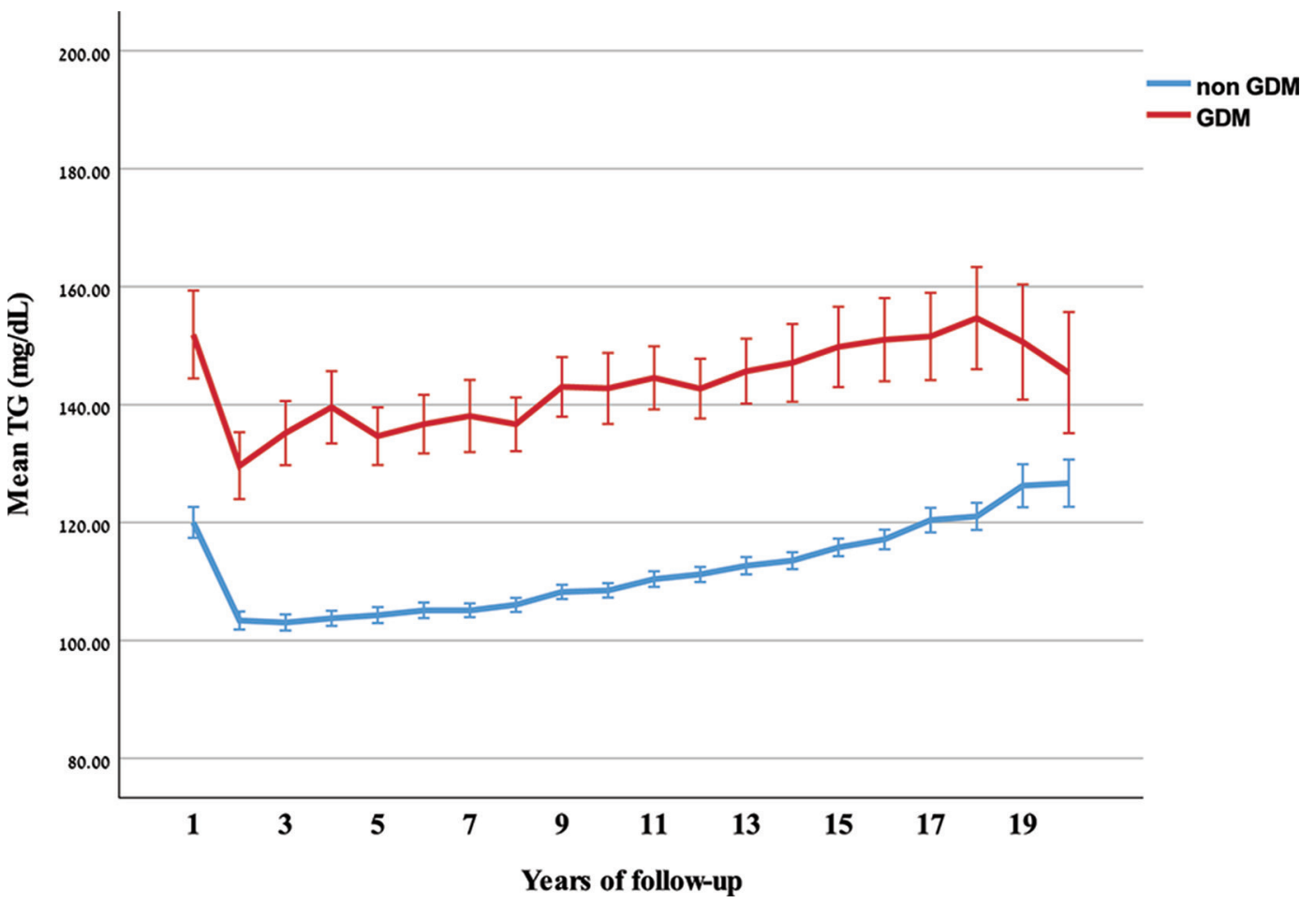

Figure 3 Mean and $95 \% \mathrm{Cl}$ of triglyceride (TG) over years of follow-up, by gestational diabetes mellitus (GDM) status.

dyslipidemia was 1.76 (95\% CI 1.28 to 2.44 ) consistent with risk estimated calculated in the current analysis.

Decreased HDL and increased TGs are components of the metabolic syndrome, which has been well described in patients with GDM. In a cohort of women $(\mathrm{n}=481)$ with previous GDM, the OR for having the metabolic syndrome according to WHO guideline was 3.4 (95\% CI 2.5 to 4.8), after adjustment for BMI and age, as compared with a population-based sample of age-matched women. ${ }^{20}$ Similar relationships have been reported in other studies. ${ }^{21}$ However, the observed association between GDM and elevated level of LDL-C, which is not specifically part of metabolic syndrome, requires more attention.

Previous analyses of LDL dyslipidemia among women with previous GDM have shown mixed results, while few studies $^{2022}{ }^{23}$ found no difference in postpartum LDL-C levels between GDM and control women without prior GDM, although some ${ }^{22} 23$ included less than 20 patients and were statistically underpowered to avoid type 2 error. Subsequent studies ${ }^{21} 24$ on larger cohorts and over longer postpartum follow-up have shown that GDM may confer an increase in LDL. In one study after 11 years of follow-up, $38 \%$ of women with GDM had LDL of $143 \mathrm{mg}$ / $\mathrm{dL}$ or more, compared with $12 \%$ of controls. The association between gestational dysglycemia idea and elevated LDL cholesterol may, thus, contribute to the risk of cardiovascular disease (CVD) in women independently to metabolic syndrome. Elevated LDL-C levels are of specific concern among women with previous GDM in light of previous studies suggesting that women with GDM were characterized by a reduced mean LDL particle size and preponderance of small dense LDL particles ${ }^{25} 26$ that has a greater atherogenic potential than that of other LDL subfractions and contributes to endothelial dysfunction and atherosclerosis that may confer further increase in risk of CVD.

Our results may therefore provide evidence to explain the increased risk of cardiovascular in women with GDM history is not totally dependent on the intercurrent development of type 2 diabetes as was reported in a recently published meta-analysis involving more than 5 million women, where women with GDM were found to have a twofold higher risk of major cardiovascular events post partum. Moreover, our finding that dyslipidemia develops soon after delivery may also explain why despite their relative young age, the risk of CVD in women with GDM was evident by as early as the first decade after delivery. Hence, our data support the emerging concept that women with previous GDM demonstrate a chronic and long-standing dyslipidemia that may contribute to the development of CVD and its manifestation. Consequently, the diagnosis of GDM provides a unique opportunity to identify future risk of vascular disease in young women at an early point in the disease's natural history, when risk modification and primary prevention may potentially be feasible.

The study has several strengths. To the best of our knowledge, this is the largest study of postpartum lipid profile both in terms of number of patients with GDM and follow-up years. Data for this cohort study were systematically collected from computerized files, which make this less likely to be a potential source of bias. The bias resulting from high dropout rate is of a greater 


\begin{tabular}{|c|c|c|}
\hline & aHR $(95 \% \mathrm{Cl})$ & $\mathrm{aHR}^{\star}(95 \% \mathrm{Cl})$ \\
\hline \multicolumn{3}{|l|}{ Outcome: TG } \\
\hline \multicolumn{3}{|l|}{ GDM } \\
\hline Yes versus no & 1.80 (1.73 to 1.88$)$ & 1.59 (1.53 to 1.66$)$ \\
\hline \multicolumn{3}{|l|}{ Age } \\
\hline Per year & 1.02 (1.01 to 1.02$)$ & 1.01 (1.01 to 1.02 ) \\
\hline \multicolumn{3}{|l|}{ BMI } \\
\hline Normal & $1(0$ to 0$)$ & $1(0$ to 0$)$ \\
\hline Overweight & 2.3 (2.2 to 2.41$)$ & 2.22 (2.12 to 2.33$)$ \\
\hline Obese & 3.32 (3.17 to 3.47 ) & 2.75 (2.63 to 2.88 ) \\
\hline \multicolumn{3}{|l|}{ Smoking } \\
\hline Never & 1 & 1 \\
\hline Past & 1.08 (0.99 to 1.19$)$ & 1.12 (1.02 to 1.23$)$ \\
\hline Current & 1.19 (1.14 to 1.24$)$ & 1.11 (1.06 to 1.15$)$ \\
\hline
\end{tabular}

\section{Outcome: LDL}

GDM

\begin{tabular}{|c|c|c|}
\hline Yes versus no & 1.45 (1.38 to 1.52$)$ & 1.35 (1.29 to 1.42$)$ \\
\hline \multicolumn{3}{|l|}{ Age } \\
\hline Per year & 1.06 (1.06 to 1.06$)$ & 1.04 (1.03 to 1.04 ) \\
\hline \multicolumn{3}{|l|}{ BMI } \\
\hline Normal & 1 & 1 \\
\hline Overweight & 1.29 (1.23 to 1.36$)$ & 1.13 (1.08 to 1.19$)$ \\
\hline Obese & 1.28 (1.21 to 1.35$)$ & 1.02 (0.97 to 1.08$)$ \\
\hline \multicolumn{3}{|l|}{ Smoking } \\
\hline Never & 1 & 1 \\
\hline Past & 1.19 (1.08 to 1.32$)$ & 1.2 (1.09 to 1.32$)$ \\
\hline Current & 1.22 (1.17 to 1.27$)$ & 0.97 (0.93 to 1.01$)$ \\
\hline \multicolumn{3}{|c|}{ Outcome: HDL-C } \\
\hline \multicolumn{3}{|l|}{ GDM } \\
\hline Yes versus no & 1.44 (1.39 to 1.5$)$ & 1.34 (1.29 to 1.39$)$ \\
\hline \multicolumn{3}{|l|}{ Age } \\
\hline Per year & 0.99 (0.98 to 0.99$)$ & 0.99 (0.99 to 1$)$ \\
\hline \multicolumn{3}{|l|}{ BMI } \\
\hline Normal & 1 & 1 \\
\hline Overweight & 1.74 (1.67 to 1.81$)$ & $1.43(1.38$ to 1.49$)$ \\
\hline Obese & 2.63 (2.53 to 2.73 ) & 1.81 (1.74 to 1.88$)$ \\
\hline \multicolumn{3}{|l|}{ Smoking } \\
\hline Never & 1 & 1 \\
\hline Past & 1.14 (1.05 to 1.23$)$ & 1.14 (1.05 to 1.23$)$ \\
\hline Current & 1.37 (1.33 to 1.42$)$ & 1.05 (1.02 to 1.08$)$ \\
\hline
\end{tabular}

*Adjusted also for baseline level of outcome lipid.

BMI, body mass index; GDM, gestational diabetes mellitus; HDL-C, high-density lipoprotein cholesterol; LDL, low-density lipoprotein; TG, triglyceride.

importance in long follow-up studies after delivery, such as the present analysis. Therefore, the very low proportion of patients untested for lipids during the follow-up period is an important study advantage. An additional strength of the present database study is the very low turnover rate of the study population (approximately $10 \%$ discontinued membership during the entire study period), affording minimal loss to follow-up. Moreover, performance of lipid tests in MHS is free and readily available to all members country-wide. Furthermore, nearly $85 \%$ of our cohort were tested for fasting blood glucose during the follow-up period, reducing the potential surveillance bias resulting from closer diabetes screening of GDM women.

The external validity of the study population to the general Israeli population should be assessed. We used the computerized data of MHS-a national health organization that provides care to $25 \%$ of the national population. It has a country-wide distribution and the membership is free and open to every citizen. Moreover, the baseline characteristics of prepregnancy baseline characteristics in our study are very similar (Cohen's $\mathrm{d}<0.1$ ) to the results of a recently published study of Jewish pregnant women in the largest health maintenance organization in Israel, ${ }^{27}$ including age (31.07 years \pm 5.08 years vs 30.9 years \pm 6.04 years $)$, HDL $(54.2 \mathrm{mg} /$ $\mathrm{dL} \pm 12.5 \mathrm{mg} / \mathrm{dL}$ vs $54.4 \mathrm{mg} / \mathrm{dL} \pm 13.3 \mathrm{mg} / \mathrm{dL}$ ), and $\mathrm{TG}$ $(104 \pm 62.5$ vs $101 \pm 57.9)$. This underscores the generalizability of our study sample.

Our study has some important limitations that should be discussed. In the present analysis we were unable to characterize fully the metabolic characteristics of the cohort before and after the index pregnancy. This includes missing information on diet, and particularly, dietary carbohydrate consumption that may have affected lipid levels. Although data on weight measurements in the index pregnancy were available for the majority of research cohorts, increased intake of rapidly absorbable carbohydrates that is positively associated with $\mathrm{GDM}^{28}$ may have explained some of the associations observed in our study. According to a recently published meta-analysis, ${ }^{29}$ exercise has no significant effect on the overall risk of GDM. Therefore, it is unlikely that our analysis was confounded by lack of information on physical activity. ${ }^{30}$

Notwithstanding these limitations, our results demonstrate that women with previous GDM present significant increase in the risk of dyslipidemia indicating that increased awareness among caregivers, as well as postnatal interventions, should begin early after delivery focusing on healthy lifestyle modification to ameliorate the excess future risk of dyslipidemia and its complications.

Contributors UE and GC were responsible for the conception and design and drafting of the article. YT, VS and YB contributed to the analysis or interpretation of study results. All coauthors have provided final approval of the version to be published.

Funding The authors have not declared a specific grant for this research from any funding agency in the public, commercial or not-for-profit sectors.

Competing interests None declared.

Patient consent for publication Not required. 
Ethics approval The study protocol was approved by the MHS Institutional Review Board for deidentified data studies.

Provenance and peer review Not commissioned; externally peer reviewed.

Data availlability statement Data are available upon reasonable request. According to Israeli regulations, no patient-level secondary used medical data can be publicly shared.

Open access This is an open access article distributed in accordance with the Creative Commons Attribution Non Commercial (CC BY-NC 4.0) license, which permits others to distribute, remix, adapt, build upon this work non-commercially, and license their derivative works on different terms, provided the original work is properly cited, appropriate credit is given, any changes made indicated, and the use is non-commercial. See: http://creativecommons.org/licenses/by-nc/4.0/.

ORCID iD

Gabriel Chodick http://orcid.org/0000-0002-5189-8995

\section{REFERENCES}

1 American Diabetes Association. 2. Classification and diagnosis of diabetes: standards of medical care in diabetes-2018. Diabetes Care 2018;41:S13-27.

2 Nielsen KK, Kapur A, Damm P, et al. From screening to postpartum follow-up - the determinants and barriers for gestational diabetes mellitus (GDM) services, a systematic review. BMC Pregnancy Childbirth 2014;14:41.

3 Ferrara A. Increasing prevalence of gestational diabetes mellitus: a public health perspective. Diabetes Care 2007;30(Suppl 2):S141-6.

4 Gilmartin ABH, Ural SH, Repke JT. Gestational diabetes mellitus. Rev Obstet Gynecol 2008;1:129.

5 Bellamy L, Casas J-P, Hingorani AD, et al. Type 2 diabetes mellitus after gestational diabetes: a systematic review and meta-analysis. Lancet 2009;373:1773-9.

6 Noctor E, Crowe C, Carmody LA, et al. Abnormal glucose tolerance post-gestational diabetes mellitus as defined by the International association of diabetes and pregnancy study groups criteria. Eur $J$ Endocrinol 2016;175:287-97

7 Kim C, Newton KM, Knopp RH. Gestational diabetes and the incidence of type 2 diabetes: a systematic review. Diabetes Care 2002;25:1862-8.

8 Chodick G, Elchalal U, Sella T, et al. The risk of overt diabetes mellitus among women with gestational diabetes: a populationbased study. Diabet Med 2010;27:779-85.

9 Xu Y, Shen S, Sun L, et al. Metabolic syndrome risk after gestational diabetes: a systematic review and meta-analysis. PLoS One 2014;9:e87863.

10 Tobias DK, Hu FB, Forman JP, et al. Increased risk of hypertension after gestational diabetes mellitus: findings from a large prospective cohort study. Diabetes Care 2011;34:1582-4.

11 Li J-W, He S-Y, Liu P, Luo L, et al. Association of gestational diabetes mellitus (GDM) with subclinical atherosclerosis: a systemic review and meta-analysis. BMC Cardiovasc Disord 2014;14:132.

12 Charach R, Wolak T, Shoham-Vardi I, et al. Can slight glucose intolerance during pregnancy predict future maternal atherosclerotic morbidity? Diabet Med 2016;33:920-5.
13 Metzger BE. Long-term outcomes in mothers diagnosed with gestational diabetes mellitus and their offspring. Clin Obstet Gynecol 2007;50:972-9.

14 Ajala O, Jensen LA, Ryan E, et al. Women with a history of gestational diabetes on long-term follow up have normal vascular function despite more dysglycemia, dyslipidemia and adiposity. Diabetes Res Clin Pract 2015;110:309-14.

15 Shostrom DCV, Sun Y, Oleson JJ, et al. History of gestational diabetes mellitus in relation to cardiovascular disease and cardiovascular risk factors in US women. Front Endocrinol 2017;8:144

16 Carpenter MW, Coustan DR. Criteria for screening tests for gestational diabetes. Am J Obstet Gynecol 1982;144:768-73.

17 Expert Panel on Detection, Evaluation, and Treatment of High Blood Cholesterol in Adults. Executive summary of the third report of the National cholesterol education program (NCEP) expert panel on detection, evaluation, and treatment of high blood cholesterol in adults (adult treatment panel III). JAMA 2001;285:2486-97.

18 Retnakaran R, Qi Y, Connelly PW, et al. The graded relationship between glucose tolerance status in pregnancy and postpartum levels of low-density-lipoprotein cholesterol and apolipoprotein B in young women: implications for future cardiovascular risk. J Clin Endocrinol Metab 2010;95:4345-53.

19 Carr DB, Utzschneider KM, Hull RL, et al. Gestational diabetes mellitus increases the risk of cardiovascular disease in women with a family history of type 2 diabetes. Diabetes Care 2006;29:2078-83.

20 Kjos SL, Buchanan TA, Montoro M, et al. Serum lipids within 36 Mo of delivery in women with recent gestational diabetes. Diabetes 1991;40 (Suppl 2):142-6.

21 Verma A, Boney CM, Tucker R, et al. Insulin resistance syndrome in women with prior history of gestational diabetes mellitus. J Clin Endocrinol Metab 2002;87:3227-35.

22 Koukkou E, Watts GF, Lowy C. Serum lipid, lipoprotein and apolipoprotein changes in gestational diabetes mellitus: a crosssectional and prospective study. J Clin Pathol 1996;49:634-7.

23 Montelongo A, Lasunción MA, Pallardo LF, et al. Longitudinal study of plasma lipoproteins and hormones during pregnancy in norma and diabetic women. Diabetes 1992;41:1651-9.

24 Meyers-Seifer $\mathrm{CH}$, Vohr BR. Lipid levels in former gestational diabetic mothers. Diabetes Care 1996;19:1351-6.

25 Qiu C, Rudra C, Austin MA, et al. Association of gestational diabetes mellitus and low-density lipoprotein (LDL) particle size. Physiol Res 2007;56:571-8.

26 Rizzo M, Berneis K, Altinova AE, et al. Atherogenic lipoprotein phenotype and LDL size and subclasses in women with gestational diabetes. Diabet Med 2008;25:1406-11.

27 Jaffe A, Giveon S, Rubin C, et al. Gestational diabetes risk in a multiethnic population. Acta Diabetol 2019;358.

28 Chen L, Hu FB, Yeung E, et al. Prospective study of pre-gravid sugar-sweetened beverage consumption and the risk of gestational diabetes mellitus. Diabetes Care 2009;32:2236-41.

29 Nasiri-Amiri F, Sepidarkish M, Shirvani MA, et al. The effect of exercise on the prevention of gestational diabetes in obese and overweight pregnant women: a systematic review and metaanalysis. Diabetol Metab Syndr 2019;11:72.

30 Bauman AE, Sallis JF, Dzewaltowski DA, et al. Toward a better understanding of the influences on physical activity: the role of determinants, correlates, causal variables, mediators, moderators, and confounders. Am J Prev Med 2002;23:5-14. 